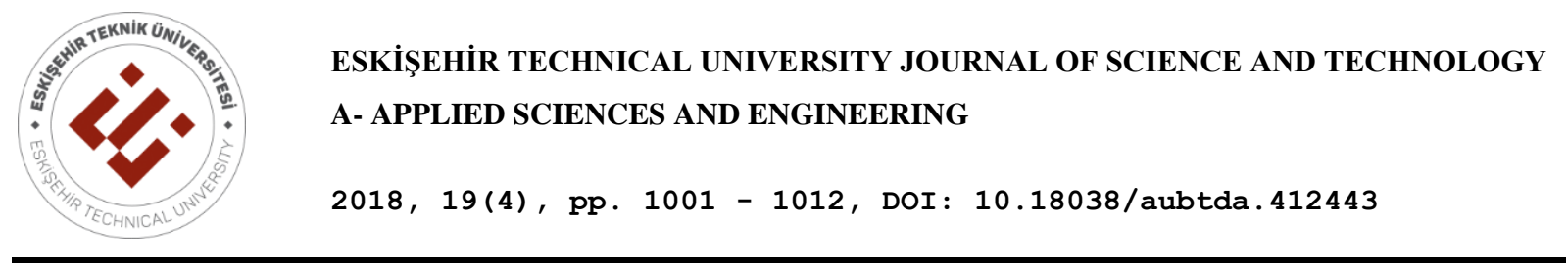

\title{
LANTHANIDE DOPED BISMUTH TUNGSTATES: AN INVESTIGATION FOR LED AND PHOTOCATALYSIS APPLICATIONS
}

\author{
Ceren YILMAZ AKKAYA ${ }^{1, \Delta}$, Uğur ÜNAL ${ }^{1, *}$ \\ ${ }^{1}$ Chemistry, Faculty of Science, Koç University, İstanbul, Turkey \\ ${ }^{2}$ Materials Science and Engineering, Graduate School of Science and Engineering, Koç University, İstanbul, Turkey \\ ${ }^{3}$ Koç University Surface Science and Technology Center, KUYTAM, İstanbul, Turkey
}

\begin{abstract}
In this work, we studied optical, photocatalytic and photoelectrochemical properties of a series of lanthanide-doped double layered Aurivillius type bismuth oxides. The visible-light harvesting photocatalysts doped with $\mathrm{Eu}, \mathrm{Pr}, \mathrm{Nd}, \mathrm{Tm}, \mathrm{Ho}$ and Ce ions were synthesized by solid-state synthesis method. Doping amount was varied between 0.2-to-10 percent. X-ray diffraction (XRD) analysis revealed that lanthanide atoms were incorporated into the $\mathrm{Bi}_{2} \mathrm{~W}_{2} \mathrm{O}_{9}$ lattice successfully up to $5 \%$. Higher dopant ratios resulted in formation of secondary phases. Particles crystallized in micro-platelet morphology. Furthermore, luminescence of $\mathrm{Pr}^{3+}$ and $\mathrm{Eu}^{3+}$ ion doped catalysts are evaluated and the study showed that red emission intensity of $\mathrm{Pr}^{3+}$ doped powder is 29 times higher than that of $\mathrm{Eu}^{3+}$ doped ceramics. Lanthanide doped powders absorb in the visible regions. Especially, doping double layered bismuth oxide with $\mathrm{Ce}$ significantly narrowed down the band gap from $\sim 3.3 \mathrm{eV}$ to $\sim 2.1 \mathrm{eV}$. Photoelectrochemical behaviour of the powders was also investigated and rare-earth dependent enhanced photocurrent production is demonstrated. Best photoelectrochemical response is achieved with $\mathrm{Tm}^{3+}$ ion doped sample.
\end{abstract}

Keywords: Perovskite oxide, Lanthanides, Luminescence, Photoelectrochemistry

\section{INTRODUCTION}

Photocatalysis is an attractive and promising future technology for renewable and sustainable energy challenge which includes clean energy production $\left(\mathrm{H}_{2}\right.$ production from water splitting), decrease in the $\mathrm{CO}_{2}$ emission levels (by $\mathrm{CO}_{2}$ reduction) and elimination of hazardous organic pollutants under solar light or other illuminating light sources. While UV absorbing $\mathrm{TiO}_{2}$-based semiconductors are the most popular choice for photocatalysis, considerable amount of semiconductors have been tested to utilize visible portion of sun light and to increase efficiency [1]. Perovskite-related layered materials that consist of two-dimensional perovskite sheets separated with cations or cationic units are among these photocatalysts. Aurivillius phase layered perovskite $\mathrm{Bi}_{2} \mathrm{WO}_{6}$ has attracted considerable attention due to its good performance in photocatalytic water splitting and dye decomposition measurements [2],[3],[12],[4]-[11]. Although, the second member of the $\mathrm{Bi}_{2} \mathrm{~W}_{\mathrm{n}} \mathrm{O}_{3 \mathrm{n}+3}$ has been reported to display photocatalytic activity over ten times higher than $\mathrm{Bi}_{2} \mathrm{WO}_{6}$ for $\mathrm{H}_{2}$ evolution and $\mathrm{O}_{2}$ evolution under $\mathrm{UV}$ radiation [13], there are few reports on $\mathrm{Bi}_{2} \mathrm{~W}_{2} \mathrm{O}_{9}$ as a photocatalyst [13]-[15]. Furthermore, the band gap energy values $\left(\mathrm{E}_{\mathrm{g}}\right)$ of $\mathrm{Bi}_{2} \mathrm{~W}_{2} \mathrm{O}_{9}$ is located between $2.87-2.96 \mathrm{eV}$ [15], hence considerable portion of solar energy cannot be utilized. Photocatalysts with wider spectral response are required for exploiting higher amount of solar energy and layered materials allow development of visible-light-active perovskites through incorporation of dopant atoms at the interlayer space or in the lattice [1]. It is well

\footnotetext{
*Corresponding Author: ugunal@ku.edu.tr

$\triangle$ Present: Koç University Surface Science and Technology Center, KUYTAM, İstanbul, Turkey

Received: 04.04.2018 Accepted: 19.11.2018
} 
known that trivalent rare earth ions with a high density of energy levels in the IR-UV range exhibit abundant absorption bands in the visible and even the infrared region. Hence, rare earth ions have been used to enhance the photocatalytic activities of metal oxides in the visible region [16],[17]. Rare earth ions have the potential to expand the visible light-response of metal oxides and decrease the recombination rate of the electron-hole through accelerated interfacial charge. Furthermore, the effect of lanthanide ion doping on the photocatalytic activity of $\mathrm{Bi}_{2} \mathrm{WO}_{6}$ has been studied [10],[18]-[20]. $\mathrm{Er}^{3+}-$ doped $\mathrm{Bi}_{2} \mathrm{WO}_{6}$ [21] and $\mathrm{BiErWO}_{6}[10]$ showed good photocatalytic performance in degradation of Rhodamine $\mathrm{B}(\mathrm{RhB})$ under simulated solar light. $\mathrm{Eu}^{3+}$-doped $\mathrm{Bi}_{2} \mathrm{WO}_{6}$ has been also shown to greatly improve photocatalytic activity [19],[22]. Rare earth-doped inorganic phosphors have also attracted attention due to their remarkable luminescent properties and applications in lighting, lasers, displays, drug carriers, photovoltaics, photocatalysis, and telecommunications [23]. Bismuth containing compounds are shown to be efficient host materials for phosphors since $\mathrm{Bi}^{3+}$ ions can be replaced by rare earth ions, which can absorb outer energy, efficiently transferring from $\mathrm{Bi}^{3+}$ to rare-earth ions [24]. To date, $\mathrm{Bi}_{2} \mathrm{WO}_{6}$ has been utilized as the host material for red-emitting phosphors by doping with $\mathrm{Eu}^{3+}$ [12] or upconversion material [21]. However, luminescence of rare-earth doped $\mathrm{Bi}_{2} \mathrm{~W}_{2} \mathrm{O}_{9}$ is rarely studied. $\mathrm{Yu} \mathrm{Li}$ et al. prepared a series of single crystal $\mathrm{LnBiW}_{2} \mathrm{O}_{9}$ compounds ( $\mathrm{Ln}: \mathrm{Ce}, \mathrm{Er}, \mathrm{Sm}, \mathrm{Eu}$ ) and studied luminescence properties of $\mathrm{EuBiW}_{2} \mathrm{O}_{9}$ [25]. The yellow-red emitting $\mathrm{EuBiW}_{2} \mathrm{O}_{9}$ has the potential to be utilized as red-emitting phosphor in light-emitting diode designs. Hence, detailed analysis of the optical properties of rare-earth doped $\mathrm{Bi}_{2} \mathrm{~W}_{2} \mathrm{O}_{9}$ compounds remains to be investigated.

In this work, we studied optical and photoelectrochemical properties of Lanthanide-doped $\mathrm{Bi}_{2} \mathrm{~W}_{2} \mathrm{O}_{9}(\mathrm{Ln}$ : $\mathrm{Eu}, \mathrm{Ce}, \mathrm{Pr}, \mathrm{Ho}, \mathrm{Tm}$ and $\mathrm{Nd}$ ) powders. The effect of dopant identity and concentration on optical and photoelectrochemical properties of the of rare-earth doped $\mathrm{Bi}_{2} \mathrm{~W}_{2} \mathrm{O}_{9}$ powders is discussed.

\section{METHODS}

\subsection{Synthesis of the Photocatalysts}

Double perovskite $\mathrm{Bi}_{2} \mathrm{~W}_{2} \mathrm{O}_{9}$ and lanthanide-doped $\mathrm{Bi}_{2} \mathrm{~W}_{2} \mathrm{O}_{9}\left(\mathrm{Ln} \_\mathrm{BWO}\right)$ nano-powders were synthesized by the traditional solid-state reaction between $\mathrm{Bi}_{2} \mathrm{O}_{3}, \mathrm{WO}_{3}$ and/or $\mathrm{Ln}_{2} \mathrm{O}_{3}(\mathrm{Ln}=\mathrm{Eu}, \mathrm{Pr}, \mathrm{Ho}, \mathrm{Tm}$ and Nd$)$ or $\mathrm{CeO}_{2}$ provided by Alfa Aesar $(99.9 \%$ ). A stoichiometric mixture prepared considering also charge neutrality was placed in a porcelain crucible and calcined at $800{ }^{\circ} \mathrm{C}$ for $48 \mathrm{~h}$ in 2-steps with intermittent grinding.

\subsection{Characterization}

Structural characterization was carried out by powder X-ray diffraction (XRD) using Bruker/D8 Advance Diffractometer with $\mathrm{Cu} \mathrm{K} \alpha$ radiation. The surface morphologies of the films were examined with ZEISS Ultraplus Field Emission Scanning Electron Microscope (FE-SEM). UV-diffuse reflectance spectra (DRS) of the oxides were measured using a Shimadzu UV-vis-NIR 3600 spectrophotometer equipped with an integration sphere. The luminescence of the powders was measured by Horiba Jobin Yvon-Fluoromax 3. Photoluminescence spectra were recorded between 370-800 nm.

\subsection{Photoelectrochemical Characterization}

Photoelectrochemical analyses were performed with Bio-Logic VSP model potentiostat/galvanostat system. The current-voltage (I-V) characteristics of the prepared films were measured under amplitude modulated-light illumination with the 3 electrode cell system with a Pt counter electrode and $\mathrm{Ag} / \mathrm{AgCl}$ (satd) reference electrode. Cyclic voltammograms (CV) were measured under a potential sweep rate of $20 \mathrm{mV} / \mathrm{s}$. $0.5 \mathrm{M} \mathrm{Na}_{2} \mathrm{SO}_{4}$ solution was used as a supporting electrolyte solution. $\mathrm{N}_{2}$ saturation was made in the electrolytes before the electrochemical measurements. The working electrodes were prepared by electrophoretic deposition (EPD). Prior to the deposition, Fluorine tin oxide 
(FTO) electrodes (Teknoma Ltd. Izmir, Turkey) were washed with acetone, ethanol and DI water, subsequently in an ultrasonic bath. Two FTO electrodes with $1 \mathrm{~cm}^{2}$ exposed areas were dipped into the suspension. The distance between the electrodes was $1 \mathrm{~cm}$. EPD was carried out under $100 \mathrm{~V}$ for 10 min. $0.02 \mathrm{~g}$ of photocatalysts were dispersed in isopropyl alcohol (IPA) containing $5 \times 10^{-4} \mathrm{M}$ aqueous $\operatorname{Mg}\left(\mathrm{NO}_{3}\right)_{2}$. EPD was carried out immediately after the suspensions were mixed in an ultrasonic bath for $30 \mathrm{~min}$. and magnetically stirred for $10 \mathrm{~min}$. Keithley 2400 Model source meter was used for deposition experiments. Following the deposition, the film was rinsed with ethanol and dried naturally.

\section{RESULTS AND DISCUSSION}

In this work, we studied photocatalytic and photoelectrochemical properties of lanthanide-doped $\mathrm{Bi}_{2} \mathrm{~W}_{2} \mathrm{O}_{9}$ powders. The effect of dopant identity and concentration on optical and photoelectrochemical properties of the powders is discussed. The doping amount ranges from 2 to $10 \mathrm{~mol} \%$ of $\mathrm{Bi}$.

\subsection{Structure}

The $\mathrm{Bi}_{2} \mathrm{~W}_{2} \mathrm{O}_{9}$ is the double layered member of the Aurivillius family of layered oxides which consists of alternating layers of $\left(\mathrm{Bi}_{2} \mathrm{O}_{2}\right)^{2+}$ and double perovskite-like $\left(\mathrm{W}_{2} \mathrm{O}_{7}\right)^{2-}$ layers. When $\mathrm{Ln}^{3+}$ ions are incorporated into the crystal lattice, the $\mathrm{Bi}^{3+}$ ion of $\left(\mathrm{Bi}_{2} \mathrm{O}_{2}\right)^{2+}$ layers are expected be substituted [4].

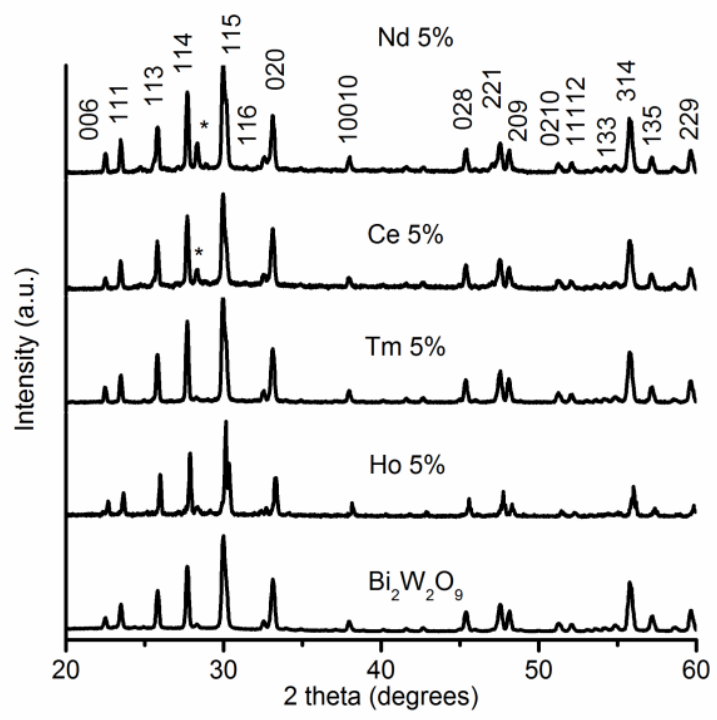

Figure 1. X-Ray powder diffraction patterns of $\mathrm{Bi}_{2} \mathrm{~W}_{2} \mathrm{O}_{9}$ and $\mathrm{Ln}_{-} \mathrm{Bi}_{2} \mathrm{~W}_{2} \mathrm{O}_{9}$ powders.

Structure and phase of the as-prepared photocatalysts were characterized by XRD measurements. XRD patterns of the as-prepared $\mathrm{Bi}_{2} \mathrm{~W}_{2} \mathrm{O}_{9}$ and $\mathrm{Ln}_{-} \mathrm{Bi}_{2} \mathrm{~W}_{2} \mathrm{O}_{9}(5 \%)$ powders match well with the reported orthorhombic structure (space group: Pna21, JCPDS 04-011-0862) accompanied by minute impurities of $\mathrm{Bi}_{2} \mathrm{WO}_{6}$ in line with literature [26] (Figure 1). No reflections that belong to secondary phases such as $\mathrm{Ln}_{2} \mathrm{O}_{3}$ or lanthanide-related forms could be detected in these XRD diagrams. Preserved orthorhombic structure and absence of $\mathrm{Ln}_{2} \mathrm{O}_{3}$ related impurities imply that lanthanide atoms were incorporated into the $\mathrm{Bi}_{2} \mathrm{~W}_{2} \mathrm{O}_{9}$ lattice. Ionic radii of lanthanide ions $-\mathrm{Eu}^{3+}(94.7 \mathrm{pm}), \mathrm{Pr}^{3+}(99 \mathrm{pm}), \mathrm{Nd}^{3+}(98.3 \mathrm{pm}), \mathrm{Tm}^{3+}$ $(88 \mathrm{pm}), \mathrm{Ho}^{3+}(90.1 \mathrm{pm})$ and $\mathrm{Ce}^{4+}(101 \mathrm{pm})$ - are smaller than that of $\mathrm{Bi}^{3+}(103 \mathrm{pm})$. Hence, substitution of $\mathrm{Bi}^{3+}$ ion with $\mathrm{Ln}^{3+}$ ions would result in reduced lattice spacing which could be detected by an increase in the observed Bragg reflections. Closer examination of diffraction patterns shows that the shift in the peak positions of $\mathrm{Ln} \_\mathrm{Bi}_{2} \mathrm{~W}_{2} \mathrm{O}_{9}$ compared with parent $\mathrm{Bi}_{2} \mathrm{~W}_{2} \mathrm{O}_{9}$ is not significant. This may be due to low amount of doping. M. Tortosa et al. showed that doping levels lower than $9 \%$ may not induce a change in the lattice parameters [27]. 


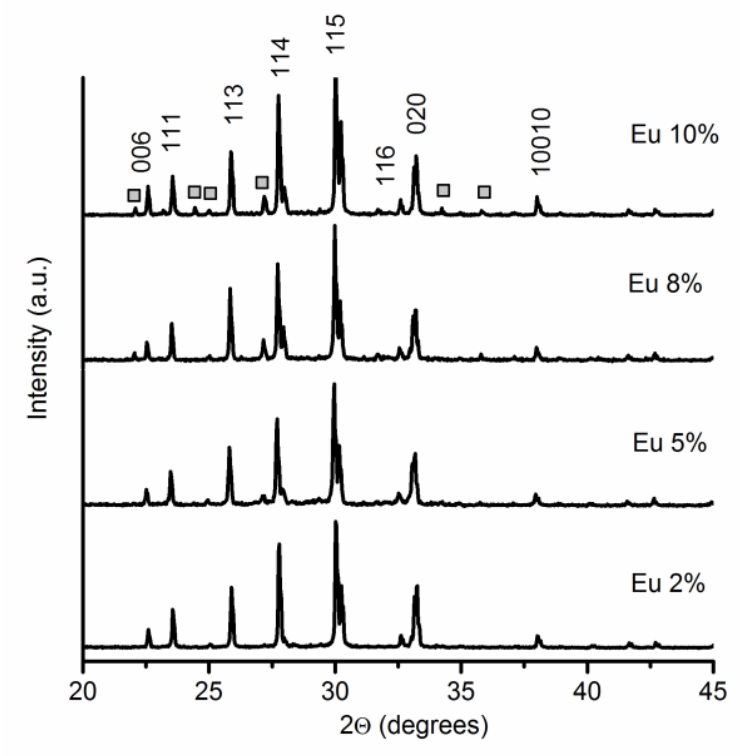

Figure 2. Eu-doped $\mathrm{Bi}_{2} \mathrm{~W}_{2} \mathrm{O}_{9}$ compounds with different doping levels.

Figure 2 displays the enlarged patterns for selected $2 \theta$ ranges of the Eu-doped $\mathrm{Bi}_{2} \mathrm{~W}_{2} \mathrm{O}_{9}$ compounds with different doping levels. No reflections that belong to secondary phases such as $\mathrm{Ln}_{2} \mathrm{O}_{3}$ or related phases could be detected in the XRD diagrams up to $5 \%$ loadings. However, signs of phase separation and formation of phases such as $\mathrm{Bi}_{12.67} \mathrm{~W}_{0.33} \mathrm{O}_{20}$ (JCPDS 04-002-5754) is observed at and above 8\% dopant levels. Similarly, $\mathrm{Pr}^{3+}$ can be incorporated to the $\mathrm{Bi}_{2} \mathrm{~W}_{2} \mathrm{O}_{9}$ structure up to $5 \%$ (Figure 3).

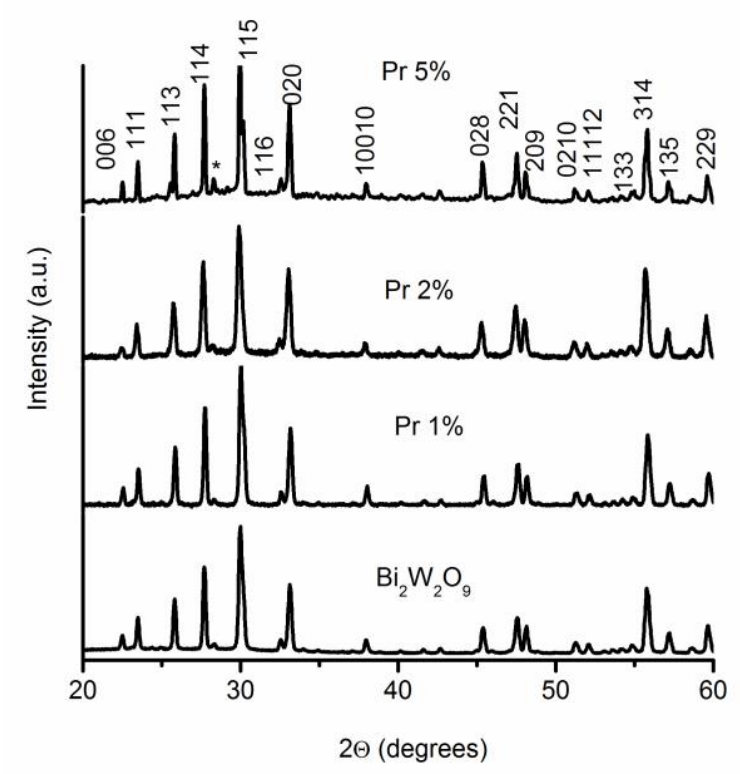

Figure 3. Pr-doped $\mathrm{Bi}_{2} \mathrm{~W}_{2} \mathrm{O}_{9}$ compounds with different doping levels.

Figure 4 depicts a typical FE-SEM image of $\mathrm{Bi}_{2} \mathrm{~W}_{2} \mathrm{O}_{9}$ powders. Microstructures are composed of wellsintered, quadrangular micro-platelets. Size of the micro-platelets vary between 1-10 $\mu \mathrm{m}$. 


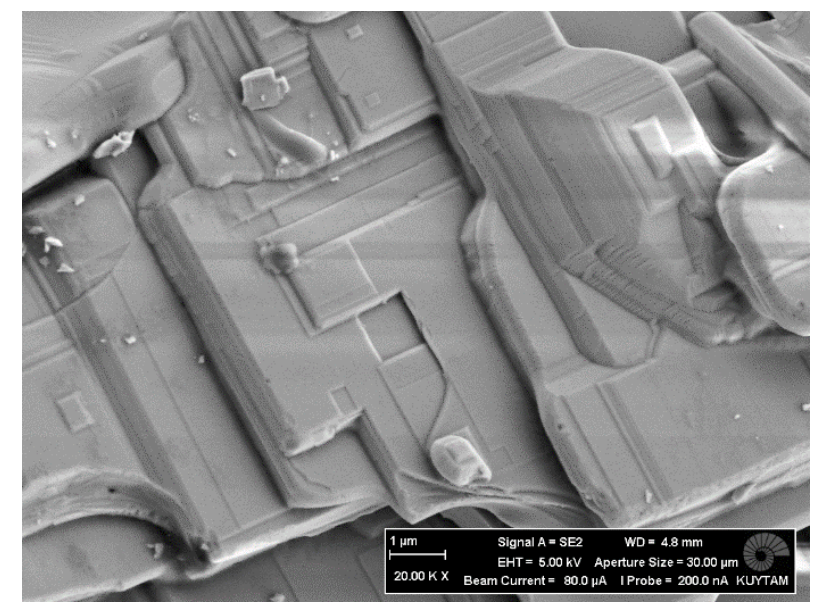

Figure 4. FE-SEM image of $\mathrm{Bi}_{2} \mathrm{~W}_{2} \mathrm{O}_{9}$.

\subsection{Optical Properties}

Transformed DRS spectra of $\mathrm{Bi}_{2} \mathrm{~W}_{2} \mathrm{O}_{9}, 2 \%$ and $10 \%$ doped samples are shown in Figure $5 . \mathrm{Bi}_{2} \mathrm{~W}_{2} \mathrm{O}_{9}$ has a steep absorption edge around $420 \mathrm{~nm}$ due to the band-edge transition (Figure 5b). All of the other samples shows this steep host absorption but it is red-shifted slightly to 435, 444 and $450 \mathrm{~nm}$ for $\mathrm{Nd}_{-}$ $\mathrm{Bi}_{2} \mathrm{~W}_{2} \mathrm{O}_{9}, \mathrm{Eu}_{-} \mathrm{Bi}_{2} \mathrm{~W}_{2} \mathrm{O}_{9}$ and $\mathrm{Pr}_{-} \mathrm{Bi}_{2} \mathrm{~W}_{2} \mathrm{O}_{9}$. Ce $\mathrm{Bi}_{2} \mathrm{~W}_{2} \mathrm{O}_{9}$ exhibited the most profound red shift to around $650 \mathrm{~nm}$ absorbing a considerable portion of visible light which accounts for the brown colour of the powder. The significant red shift suggests narrower band gap for $\mathrm{Ce}_{-} \mathrm{Bi}_{2} \mathrm{WO}_{9}$ which is attributed to charge transfer between the valance band of the host and $4 \mathrm{f}$ levels of the Ce ion [28]. Y. Li et al, reported $\mathrm{EuBiW}_{2} \mathrm{O}_{9}, \mathrm{ErBiW}_{2} \mathrm{O}_{9}, \mathrm{SmBiW}_{2} \mathrm{O}_{9}$, and $\mathrm{CeBiW}_{2} \mathrm{O}_{9}$ to be indirect band gap materials based on DFT calculations [25]. Hence, the optical band gap energy of the powders were calculated by Tauc plot [29], assuming indirect allowed transition. $\left[\mathrm{F}_{\mathrm{KM}}(\mathrm{R}) \cdot \mathrm{h} v\right]^{1 / 2}$ was plotted against the photon energy, where $\mathrm{F}(\mathrm{R})$ is Kubelka-Munk function and $\mathrm{h} v$ is incident photon energy. The band gap energies for pristine, $\mathrm{Nd}_{-}$ $\mathrm{Bi}_{2} \mathrm{~W}_{2} \mathrm{O}_{9}, \mathrm{Eu}_{-} \mathrm{Bi}_{2} \mathrm{~W}_{2} \mathrm{O}_{9}, \mathrm{Pr}_{-} \mathrm{Bi}_{2} \mathrm{~W}_{2} \mathrm{O}_{9} . \mathrm{Ce}_{-} \mathrm{Bi}_{2} \mathrm{~W}_{2} \mathrm{O}_{9}$ products are 3.18, 3.19, 3.17, 3.16 and $2.11 \mathrm{eV}$, respectively suggesting especially $\mathrm{Ce}_{-} \mathrm{Bi}_{2} \mathrm{~W}_{2} \mathrm{O}_{9}$ to be a promising visible-light photocatalyst. 
a)

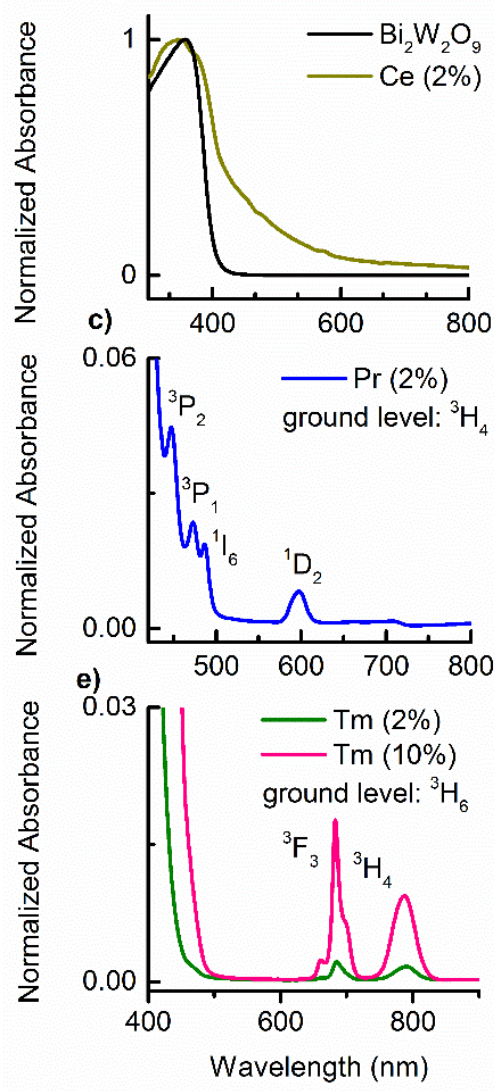

b)
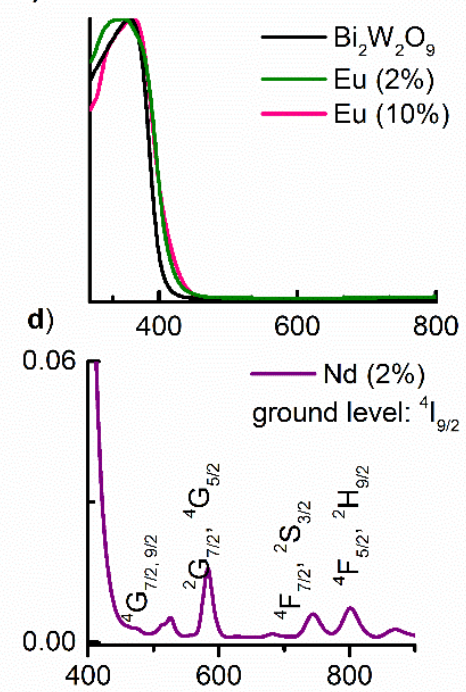

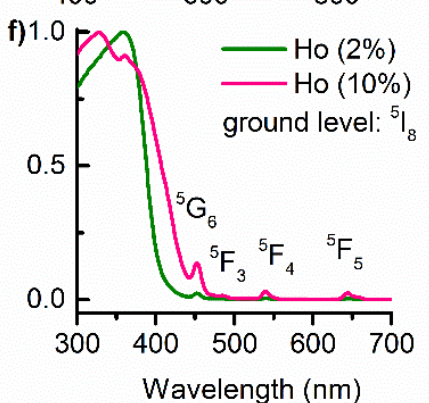

Figure 5. UV-vis absorbance spectra of a) $\mathrm{Bi}_{2} \mathrm{~W}_{2} \mathrm{O}_{9}$ and $\mathrm{Ce} \_\mathrm{Bi}_{2} \mathrm{~W}_{2} \mathrm{O}_{9}$, b) $\mathrm{Eu}_{-} \mathrm{Bi}_{2} \mathrm{~W}_{2} \mathrm{O}_{9}$, c) $\mathrm{Pr}_{-} \mathrm{Bi}_{2} \mathrm{~W}_{2} \mathrm{O}_{9}$, d) Nd_Bi ${ }_{2} \mathrm{~W}_{2} \mathrm{O}_{9}$, e) $\left.\mathrm{Tm} \_\mathrm{Bi}_{2} \mathrm{~W}_{2} \mathrm{O}_{9}, \mathrm{f}\right) \mathrm{Ho} \_\mathrm{Bi}_{2} \mathrm{~W}_{2} \mathrm{O}_{9}$ powders.

In addition to the slight shift of the host absorption peak, some characteristic transitions of the lanthanide ions are observed for $\mathrm{Pr}_{-} \mathrm{Bi}_{2} \mathrm{WO}_{9}, \mathrm{Nd}_{-} \mathrm{Bi}_{2} \mathrm{WO}_{9}, \mathrm{Tm}_{-} \mathrm{Bi}_{2} \mathrm{WO}_{9}$ and $\mathrm{Ho}_{-} \mathrm{Bi}_{2} \mathrm{~W}_{2} \mathrm{O}_{9}$ as indicated by the sharp absorption peaks in the visible region (Figure 4). Peaks observed at 447, 472, 486 and $597 \mathrm{~nm}$ for $\mathrm{Pr}_{-} \mathrm{Bi}_{2} \mathrm{~W}_{2} \mathrm{O}_{9}$ are ascribed to the transitions from ground state of $\mathrm{Pr}^{3+},{ }^{3} \mathrm{H}_{4}$, to ${ }^{3} \mathrm{P}_{2},{ }^{1} \mathrm{I}_{6},{ }^{3} \mathrm{P}_{1},{ }^{3} \mathrm{P}_{0}$ and ${ }^{1} \mathrm{D}_{2}$, respectively [8]. Characteristic absorption bands of $\mathrm{Nd}^{3+}$ ions originating from the ground state, ${ }^{4} \mathrm{I}_{9 / 2}$, to higher excited states, ${ }^{4} \mathrm{G}_{7 / 2}, 9 / 2,{ }^{4} \mathrm{G}_{5 / 2}+{ }^{2} \mathrm{G}_{7 / 2},{ }^{4} \mathrm{~F}_{7 / 2},{ }^{2} \mathrm{H}_{9 / 2}+{ }^{4} \mathrm{~F}_{5 / 2},{ }^{4} \mathrm{~F}_{3 / 2}$, at 526, 583, 745, 801 and $870 \mathrm{~nm}$ can also be seen in Figure 4d [30]. The bands present in the absorption spectrum of $\mathrm{Tm}_{-} \mathrm{Bi}_{2} \mathrm{WO}_{9}$ centred at 685 and $789 \mathrm{~nm}$ can be indexed to the transitions from the ground level, ${ }^{3} \mathrm{H}_{6}$, to ${ }^{3} \mathrm{~F}_{3}$ and ${ }^{3} \mathrm{H}_{6}$, respectively [31]. The spectrum of $\mathrm{Ho}_{-} \mathrm{Bi}_{2} \mathrm{WO}_{9}$ exhibits absorption bands in the visible region centred at $453,453,540$ and $645 \mathrm{~nm}$, which correspond to the transitions from ground state, ${ }^{5} \mathrm{I}_{8}$, to upper levels; ${ }^{5} \mathrm{G}_{6},{ }^{5} \mathrm{~F}_{4}$ and ${ }^{5} \mathrm{~F}_{5}$, respectively [7]. In addition, the intensity of absorption bands of the rare earth ions is found to increase with increasing rare earth content as exemplified with Tm and Ho doped powders (Figure 5). The transitions of $4 \mathrm{f}$ electrons of the rare earth ions are expected to favour the separation of the photogenerated charge carriers which decreases the electron-hole recombination rate, thereby enhancing the photocurrent production efficiency. Moreover, the slightly red-shifted absorption edge as discussed above is considered to improve the photocatalytic activity under visible light [4],[32],[33].

Photoluminescence spectra of dispersed $\mathrm{Pr}_{-} \mathrm{Bi}_{2} \mathrm{~W}_{2} \mathrm{O}_{9}$ and $\mathrm{Eu}_{-} \mathrm{Bi}_{2} \mathrm{~W}_{2} \mathrm{O}_{9}$ powders with varying dopant amounts were measured at room temperature (Figure 6). Emission profiles of $\mathrm{Eu}_{-} \mathrm{Bi}_{2} \mathrm{~W}_{2} \mathrm{O}_{9}$ powders depend on the excitation energy (Figure $6 \mathrm{~b}-\mathrm{c}$ ). Upon excitation at $350 \mathrm{~nm}, \mathrm{Eu}_{-} \mathrm{Bi}_{2} \mathrm{~W}_{2} \mathrm{O}_{9}$ powders exhibit a number of emission bands in the range of $550-700 \mathrm{~nm}$ which originate from ${ }^{5} \mathrm{D}_{0} \rightarrow{ }^{7} \mathrm{~F}_{\mathrm{J}}(\mathrm{J}=0,1,2,3)$ transitions of $\mathrm{Eu}^{3+}$ ion. The peaks at $\sim 580,588-596,614-625$ and $652 \mathrm{~nm}$ are indexed to $J=0, J=1, J$ $=2$ and $J=3$, respectively with maximum emission at $\sim 614 \mathrm{~nm}$. The relative intensity of $614 \mathrm{~nm}$ emission line increases at the expense of the others when the sample is exited at $254 \mathrm{~nm}$. Information 
regarding the local environment of $\mathrm{Eu}^{3+}$ ion in the host can be deduced from relative intensities of these emission lines [23],[34],[35]. The ${ }^{5} \mathrm{D}_{0} \rightarrow{ }^{7} \mathrm{~F}_{0}$ transition at around $580 \mathrm{~nm}$ (observed under illumination at $350 \mathrm{~nm}$ ) indicates a very low point group symmetry around $\mathrm{Eu}^{3+}$ ion in $\mathrm{Bi}_{2} \mathrm{~W}_{2} \mathrm{O}_{9}$ since it is forbidden both by electric and magnetic dipole [25],[36]. The electric dipole (ED) transition, ${ }^{5} \mathrm{D}_{0} \rightarrow{ }^{7} \mathrm{~F}_{2}$, is forbidden for the free ion or in the presence of inversion symmetry [34]. Hence, the induced ED transition is hypersensitive to the crystal field environment and its emission intensity is strongly affected by the strength of local electric field. Even small deviations from inversion symmetry will result in dominant red emission [37]. On the other hand, ${ }^{5} \mathrm{D}_{0} \rightarrow{ }^{7} \mathrm{~F}_{1}$ transition is magnetic dipole (MD) allowed and insensitive to the crystal environment. Therefore, the intensity ratio of $\mathrm{ED}\left({ }^{5} \mathrm{D}_{0} \rightarrow{ }^{7} \mathrm{~F}_{2}\right)$ to $\mathrm{MD}\left({ }^{5} \mathrm{D}_{0} \rightarrow{ }^{7} \mathrm{~F}_{1}\right)$ transition (red to orange emission) which is defined as the asymmetry ratio serves as a measure of the site symmetry of the $\mathrm{Eu}^{3+}$ ions in the host crystals. This value is reported to be 0.67 for centrosymmetric $\mathrm{Eu}^{3+}$ ion and higher values imply lower symmetry [38]. It is reported that the ${ }^{5} \mathrm{D}_{0} \rightarrow{ }^{7} \mathrm{~F}_{0}$ transition is only observed with $\mathrm{C}_{\mathrm{n}}, \mathrm{C}_{\mathrm{nv}}$ and $\mathrm{C}_{\mathrm{s}}$ symmetry [36]. Furthermore, the integral intensity ratio of ${ }^{5} \mathrm{D}_{0} \rightarrow{ }^{7} \mathrm{~F}_{2}$ to ${ }^{5} \mathrm{D}_{0} \rightarrow{ }^{7} \mathrm{~F}_{1}$ transition is calculated to be 1.70 for $5 \% \mathrm{Eu}_{-} \mathrm{Bi}_{2} \mathrm{~W}_{2} \mathrm{O}_{9}$ (and 1.75 for $2 \% \mathrm{Eu}_{-} \mathrm{Bi}_{2} \mathrm{~W}_{2} \mathrm{O}_{9}$ ) for excitation at $350 \mathrm{~nm}$ and 4.9 and 2.5 for excitation at $254 \mathrm{~nm}$, respectively. Hence, this emission profile (Figure 6b) implies that the local symmetry around $\mathrm{Eu}^{3+}$ ion in $\mathrm{Bi}_{2} \mathrm{~W}_{2} \mathrm{O}_{9}$ is without an inversion centre. This is in line with XRD studies which suggest substitution of rare earth atoms in the crystal structure since all atoms in $\mathrm{Bi}_{2} \mathrm{~W}_{2} \mathrm{O}_{9}$ are reported to occupy $C_{1}$ symmetry sites [39].

a)

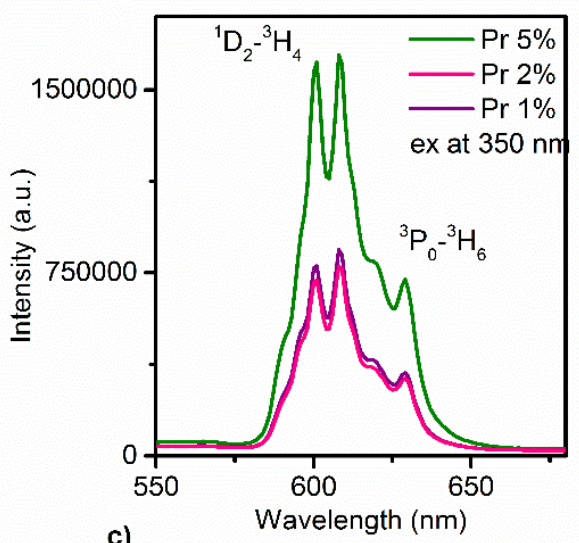

c)

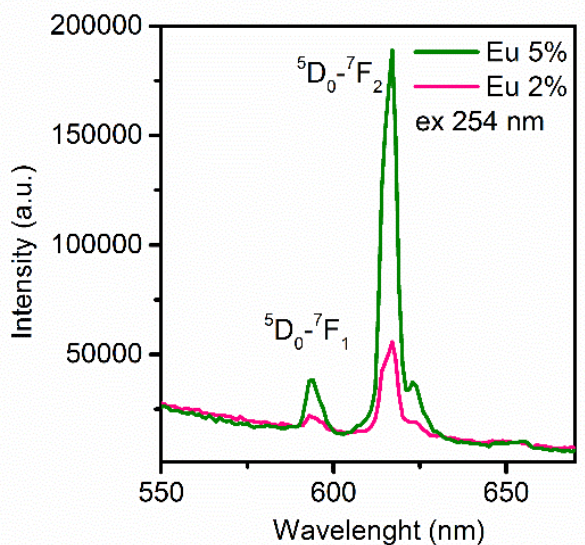

b)

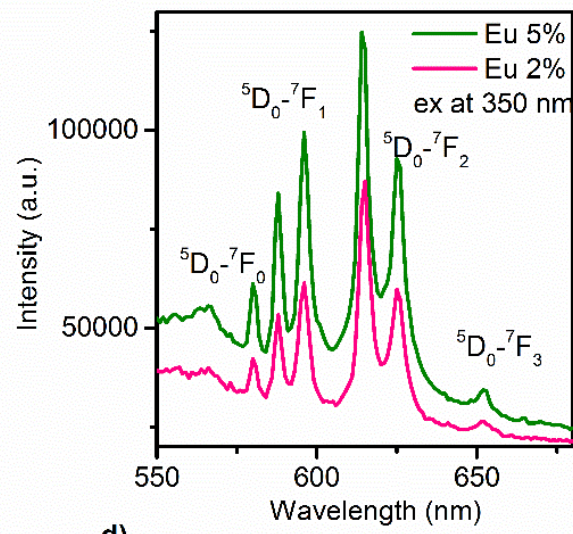

d)

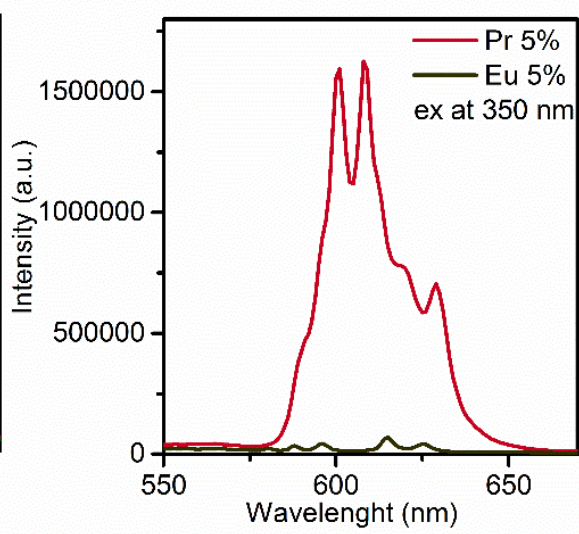

Figure 6. Photoluminescence spectra of a) $\mathrm{Pr}_{-} \mathrm{Bi}_{2} \mathrm{~W}_{2} \mathrm{O}_{9}$ and b) $\mathrm{Eu}_{-} \mathrm{Bi}_{2} \mathrm{~W}_{2} \mathrm{O}_{9}$ powders dispersed in distilled water and exited at $350 \mathrm{~nm}$, c) $\mathrm{Eu}_{-} \mathrm{Bi}_{2} \mathrm{~W}_{2} \mathrm{O}_{9}$ powders dispersed in distilled water and exited at $254 \mathrm{~nm}, \mathrm{~d}$ ) luminescence intensity difference between $\mathrm{Pr}_{-} \mathrm{Bi}_{2} \mathrm{~W}_{2} \mathrm{O}_{9}$ and $\mathrm{Eu}_{-} \mathrm{Bi}_{2} \mathrm{~W}_{2} \mathrm{O}_{9}$.

We also report luminescence properties of $\mathrm{Bi}_{2} \mathrm{~W}_{2} \mathrm{O}_{9}$ powders doped with $\mathrm{Pr}^{3+}$ ions for the first time, to the best of our knowledge. In the emission spectra $\mathrm{Pr}_{-} \mathrm{Bi}_{2} \mathrm{~W}_{2} \mathrm{O}_{9}$ powders under $350 \mathrm{~nm}$ excitation, the emission bands of ${ }^{1} \mathrm{D}_{2} \rightarrow{ }^{3} \mathrm{H}_{4}$ display sharp peaks at around 601, 608, 620 (a weak shoulder) and 629 
$\mathrm{nm}$ with due to characteristic de-excitation of ${ }^{1} \mathrm{D}_{2}$ multiplets of $\operatorname{Pr}^{3+}$ ion [40]. The strongest emission is at $608 \mathrm{~nm}$ with excitation with UV light, which implies effective energy transfer between the host and the lanthanide ion. Furthermore, emission intensity increases with dopant amount for both $\mathrm{Eu}^{3+}$ and $\mathrm{Pr}^{3+}$ doped samples. The red emission intensity of $\mathrm{Pr}^{3+}$ doped powder is 29 times higher than that of $\mathrm{Eu}^{3+}$ doped ceramics (integral area). Hence, $\mathrm{Pr}_{-} \mathrm{Bi}_{2} \mathrm{~W}_{2} \mathrm{O}_{9}$ with its intense red emission is a better candidate than $\mathrm{Eu}_{-} \mathrm{Bi}_{2} \mathrm{~W}_{2} \mathrm{O}_{9}$ for utilization as red phosphor in designing white light -emitting diodes with highly intense emissions (Figure 6c).

\subsection{Photoelectrochemical Properties}

The photoelectrochemical properties of the electrodes prepared by electrophoretic deposition is investigated through transient photocurrent studies and linear voltammetry. Figure 7a shows the linear voltammetry scans $(25 \mathrm{mV} / \mathrm{s})$ of $\mathrm{Bi}_{2} \mathrm{~W}_{2} \mathrm{O}_{9}$ and $\mathrm{Ln}(2 \%)_{-} \mathrm{Bi}_{2} \mathrm{~W}_{2} \mathrm{O}_{9}$ under pulsed illumination. The onset potential of the photocurrent was observed to appear at around $-0.2 \mathrm{~V}$ (except for $\mathrm{Ho}_{-} \mathrm{Bi}_{2} \mathrm{~W}_{2} \mathrm{O}_{9}$ ), and the photocurrent increased steadily with applied positive potential. The net photocurrent density $\left(\mathrm{I}_{\text {photocurrent }}{ }^{-}\right.$ $\mathrm{I}_{\text {dark current }}$ ) produced by pure $\mathrm{Bi}_{2} \mathrm{~W}_{2} \mathrm{O}_{9}$ is higher than that of $\mathrm{Eu}_{-} \mathrm{Bi}_{2} \mathrm{~W}_{2} \mathrm{O}_{9}$ and $\mathrm{Pr}_{-} \mathrm{Bi}_{2} \mathrm{~W}_{2} \mathrm{O}_{9}$ while $\mathrm{Ce} \_\mathrm{Bi}_{2} \mathrm{~W}_{2} \mathrm{O}_{9}, \mathrm{Nd} \_\mathrm{Bi}_{2} \mathrm{~W}_{2} \mathrm{O}_{9}$ and $\mathrm{Tm}_{-} \mathrm{Bi}_{2} \mathrm{~W}_{2} \mathrm{O}_{9}$ show enhanced photoelectrochemical activity than their undoped counterpart. The lower photocurrent suggests increased electron-hole recombination for $\mathrm{Eu}_{-}$ $\mathrm{Bi}_{2} \mathrm{~W}_{2} \mathrm{O}_{9}$ and $\mathrm{Pr}_{-} \mathrm{Bi}_{2} \mathrm{~W}_{2} \mathrm{O}_{9}$. As discussed in the previous section, $\mathrm{Bi}_{2} \mathrm{~W}_{2} \mathrm{O}_{9}$ is very effective in absorbing $\mathrm{UV}$ light and transferring energy to $\mathrm{Eu}^{3+}$ and $\mathrm{Pr}^{3+}$ ions which results in strong luminescence. The exited electrons might be back-donated to the defect/donor band and recombine with the holes in the valance band, thereby decreasing photoelectrochemical efficiency. $\mathrm{Ce}_{-} \mathrm{Bi}_{2} \mathrm{~W}_{2} \mathrm{O}_{9}, \mathrm{Nd}_{-} \mathrm{Bi}_{2} \mathrm{~W}_{2} \mathrm{O}_{9}$ and $\mathrm{Tm}$ $\mathrm{Bi}_{2} \mathrm{~W}_{2} \mathrm{O}_{9}$, on the other hand, are more effective in separation of photogenerated electron-hole pairs than pure $\mathrm{Bi}_{2} \mathrm{~W}_{2} \mathrm{O}_{9}$. As discussed above, rather than inducing structural changes or forming impurity phases, lanthanide ions are incorporated into the $\mathrm{Bi}_{2} \mathrm{~W}_{2} \mathrm{O}_{9}$ lattice when the doping amount is $2 \%$. The incorporation of lanthanide ions could form shallow energy level(s) between the conductance and valance band of $\mathrm{Bi}_{2} \mathrm{~W}_{2} \mathrm{O}_{9}$, extending both its light absorption to visible region and lifetime of the charge carriers. Accordingly, incorporation of $\mathrm{Ce}, \mathrm{Nd}$ and $\mathrm{Tm}$ ions into the structure enhances the photoelectrochemical property of the $\mathrm{Bi}_{2} \mathrm{~W}_{2} \mathrm{O}_{9}$ electrode. Among these photocatalysts, $\mathrm{Tm}_{-} \mathrm{Bi}_{2} \mathrm{~W}_{2} \mathrm{O}_{9}$ exhibited highest photoactivity with $1.34 \mu \mathrm{A} / \mathrm{cm}^{2}$ net photocurrent density at $0.5 \mathrm{~V}$ under $75 \mathrm{~mW} / \mathrm{cm}^{2}$ light. Interestingly, decrease in the photoelectrochemical performance of $\mathrm{Tm}_{-} \mathrm{Bi}_{2} \mathrm{~W}_{2} \mathrm{O}_{9}$ is observed with the increase of thulium ions content (Figure 7b). As explained above, impurity phases start to appear when loading amount is above 5\%. These defect sites together with the excess lanthanide ions might act as recombination centres and reduce the efficiency of charge separation. The photoactivity of the films under simulated solar light and visible light irradiation is also measured. The spectral distribution of Xenon lamp light is extended beyond $300 \mathrm{~nm}$ (until $250 \mathrm{~nm}$ ) as opposed to global AM 1.5 sunlight that begins at $300 \mathrm{~nm}$. Furthermore, the spectral distribution of Xenon lamp light is higher in the UV region, but lower in the visible region when compared to sunlight [41]. Hence, relatively higher values for photocurrent density and photoconversion efficiency under Xenon lamp illumination will be expected for $\mathrm{Bi}_{2} \mathrm{~W}_{2} \mathrm{O}_{9}$ samples compared to those under sunlight or visible light since although lanthanide incorporation provides absorption of visible light to some extent, the absorbance of the powders in the $\mathrm{UV}$ region is stronger. As expected, the photocurrent density is decreased to 0.3 of the photocurrent density under 1 sun conditions and to 0.02 of it under visible light irradiation for all of the photocatalysts, as exemplified by $\mathrm{Nd}_{-} \mathrm{Bi}_{2} \mathrm{~W}_{2} \mathrm{O}_{9}$ in Figure 7c. 

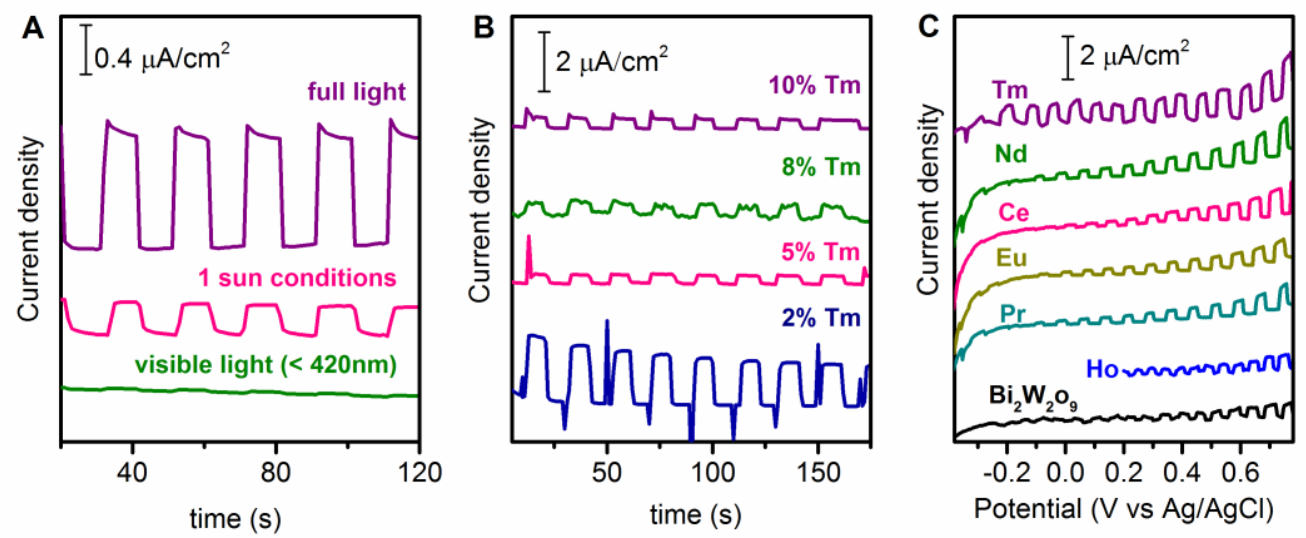

Figure 7. Photoresponses of the photocatalysts under $75 \mathrm{~mW} / \mathrm{cm}^{2}$, amplitude modulated illumination in $0.5 \mathrm{M}$ $\mathrm{K}_{2} \mathrm{SO}_{4}$ a) J-V curves of $\mathrm{Ln}_{-} \mathrm{Bi}_{2} \mathrm{~W}_{2} \mathrm{O}_{9}$ electrodes, b) Photoresponses of $\mathrm{Bi}_{2} \mathrm{~W}_{2} \mathrm{O}_{9}$ doped with varying Tm concentration under $75 \mathrm{~mW} / \mathrm{cm}^{2}$, amplitude modulated illumination, c) Photoresponses of $\mathrm{Nd}_{-} \mathrm{Bi}_{2} \mathrm{~W}_{2} \mathrm{O}_{9}$ films at $0.5 \mathrm{~V}$ (vs. $\mathrm{Ag} / \mathrm{AgCl}$ ) under $75 \mathrm{~mW} / \mathrm{cm}^{2} \mathrm{Xe}$ lamp, simulated sun light and visible light illumination.

\section{CONCLUSIONS}

A series of lanthanide-doped double layered Aurivillius type bismuth oxides were prepared by solidstate synthesis. XRD diagrams revealed that introduction of lanthanide ions did not induce structural changes or result in impurity phases up to $5 \%$ loadings. The local symmetry around $\mathrm{Eu}^{3+}$ ion in $\mathrm{Bi}_{2} \mathrm{~W}_{2} \mathrm{O}_{9}$ together with XRD studies suggested that substitution of rare earth atoms in the crystal structure in the $\mathrm{Bi}^{3+}$ sites. $\mathrm{Pr}_{-} \mathrm{Bi}_{2} \mathrm{~W}_{2} \mathrm{O}_{9}$ and $\mathrm{Eu}_{-} \mathrm{Bi}_{2} \mathrm{~W}_{2} \mathrm{O}_{9}$ powders displayed very strong red emission although luminesce intensity of $\mathrm{Pr}_{-} \mathrm{Bi}_{2} \mathrm{~W}_{2} \mathrm{O}_{9}$ is much higher as compared to that of $\mathrm{Eu}_{-} \mathrm{Bi}_{2} \mathrm{~W}_{2} \mathrm{O}_{9}$. Among the prepared photocatalysts, $\mathrm{Tm}(2 \%) \mathrm{Bi}_{2} \mathrm{~W}_{2} \mathrm{O}_{9}$ exhibited highest photoactivity with $1.34 \mu \mathrm{A} / \mathrm{cm}^{2}$ net photocurrent density at $0.5 \mathrm{~V}$ under $75 \mathrm{~mW} / \mathrm{cm}^{2}$ light, suggesting enhanced charge carrier separation with introduction of $\mathrm{Tm}$ into the structure.

\section{ACKNOWLEDGEMENTS}

Authors thank to The Scientific and Technological Research Council of Turkey (TUBITAK) for funding through project 114Z452. We also thank to Turkish Ministry of Development for the financial support provided for the establishment of Koç University Surface Science and Technology Center (KUYTAM).

\section{REFERENCES}

[1] Kubacka A, Fernández-García M, Colón G. Advanced nanoarchitectures for solar photocatalytic applications. Chem Rev 2012; 112: 1555-1614.

[2] Zhang Q, Sun H, Wang X, Zhang Y, Li X. Strong photoluminescence and piezoelectricity properties in Pr-doped $\mathrm{Ba}\left(\mathrm{Zr}_{0.2} \mathrm{Ti}_{0.8}\right) \mathrm{O}_{3}-\left(\mathrm{Ba}_{0.7} \mathrm{Ca}_{0.3}\right) \mathrm{TiO}_{3}$ ceramics: Influence of concentration and microstructure. J Eur Ceram Soc 2014; 34: 1439-1444.

[3 ] MạcZka M, MacAlik L, Kojima S. Temperature-dependent Raman scattering study of cationdeficient Aurivillius phases: $\mathrm{Bi}_{2} \mathrm{WO}_{6}$ and $\mathrm{Bi}_{2} \mathrm{~W}_{2} \mathrm{O}_{9}$. J Phys Condens Matter 2011; 23.

[4] Tian N, Zhang Y, Huang H, He Y, Guo Y. Influences of Gd substitution on the crystal structure 
and visible-light-driven photocatalytic performance of $\mathrm{Bi}_{2} \mathrm{WO}_{6}$. J Phys Chem C 2014; 118: 1564015648.

[5 ] Guan M, He X, Shang T, Sun J, Zhou Q. Hydrothermal synthesis of ultrathin $\mathrm{Bi}_{2} \mathrm{MO}_{6}(\mathrm{M}=\mathrm{W}, \mathrm{Mo})$ nanoplates as new host substances for red-emitting europium ion. Prog Nat Sci Mater Int 2012; 22: 334-340.

[6] Zhang ZJ, Chen XY. $\mathrm{Sb}_{2} \mathrm{MoO}_{6}, \mathrm{Bi}_{2} \mathrm{MoO}_{6}, \mathrm{Sb}_{2} \mathrm{WO}_{6}$, and $\mathrm{Bi}_{2} \mathrm{WO}_{6}$ flake-like crystals: Generalized hydrothermal synthesis and the applications of $\mathrm{Bi}_{2} \mathrm{WO}_{6}$ and $\mathrm{Bi}_{2} \mathrm{MoO}_{6}$ as red phosphors doped with $\mathrm{Eu}^{3+}$ ions. Mater Sci Eng B 2016; : 1-7.

[7 ] Venkateswarlu M, Mahamuda S, Swapna K, Prasad MVVKS, Srinivasa Rao A, Shakya S, Mohan Babu A, Vijaya Prakash G. Holmium doped Lead Tungsten Tellurite glasses for green luminescent applications. J Lumin 2015; 163: 64-71.

[8 ] Tkachuk AM, Ivanova SE, Mirzaeva AA, Joubert M-F, Guyot Y. Spectroscopic characteristics of praseodymium-doped cubic double sodium-yttrium fluoride crystals $\mathrm{Na}_{0.4} \mathrm{Y}_{0.6} \mathrm{~F}_{2.2}: \mathrm{Pr}^{3+}$. Intensities of optical transitions and luminescence kinetics. Opt Spectrosc 2014; 116: 392-407.

[9] Huang H, Liu K, Chen K, Zhang Y, Zhang Y, Wang S. Ce and F Comodification on the Crystal Structure and Enhanced Photocatalytic Activity of $\mathrm{Bi}_{2} \mathrm{WO}_{6}$ Photocatalyst under Visible Light Irradiation. J Phys Chem C 2014; : 140624153631000.

[10] Zhang Z, Wang W, Zhou Y. Hydrothermal synthesis of a novel BiErWO 6 photocatalyst with wide spectral responsive property. Appl Surf Sci 2014; 319: 250-255.

[11] Su Y, Tan G, Xu C, Liu T, Wang Y, Ren H, Xia A. The up-conversion effect induced NIRphotocatalytic performance of $\mathrm{Bi}_{2-\mathrm{x}} \mathrm{Er}_{\mathrm{x}} \mathrm{WO}_{6}$ photocatalysts. Mater Lett 2018; 211: 175-178.

[12] Gu H, Yu L, Wang J, Ni M, Liu T, Chen F. Tunable luminescence and enhanced photocatalytic activity for $\mathrm{Eu}(\mathrm{III})$ doped $\mathrm{Bi}_{2} \mathrm{WO}_{6}$ nanoparticles. Spectrochim Acta - Part A Mol Biomol Spectrosc 2017; 177: 58-62.

[13] Kudo A, Hijii S. $\mathrm{H}_{2}$ or $\mathrm{O}_{2}$ Evolution from Aqueous Solutions on Layered Oxide Photocatalysts Consisting of $\mathrm{Bi}^{3+}$ with $6 \mathrm{~s}^{2}$ Configuration and $\mathrm{d}^{0}$ Transition Metal Ions. Chem Lett 1999; 28 : $1103-$ 1104.

[14] Cruz AM, Alfaro SO, Torres-Martínez LM, Ramírez IJ. Synthesis of $\mathrm{Bi}_{2} \mathrm{~W}_{2} \mathrm{O}_{9}$ from an amorphous complex precursor: characterization and evaluation of its photocatalytical properties. J Ceram Process Res 2008; 9: 490-494.

[15] Alfaro SO, Martínez-De La Cruz A. Synthesis, characterization and visible-light photocatalytic properties of $\mathrm{Bi}_{2} \mathrm{WO}_{6}$ and $\mathrm{Bi}_{2} \mathrm{~W}_{2} \mathrm{O}_{9}$ obtained by co-precipitation method. Appl Catal A Gen 2010; 383: $128-133$.

[16] Gionco C, Paganini MC, Giamello E, Sacco O, Vaiano V, Sannino D. Rare earth oxides in zirconium dioxide: How to turn a wide band gap metal oxide into a visible light active photocatalyst. J Energy Chem 2017; 26: 270-276.

[17] Sin JC, Lam SM, Lee KT, Mohamed AR. Preparation of rare earth-doped ZnO hierarchical micro/nanospheres and their enhanced photocatalytic activity under visible light irradiation. Ceram Int 2014; 40: 5431-5440. 
[18] Zhang Z, Wang W, Yin W, Shang M, Wang L, Sun S. Inducing photocatalysis by visible light beyond the absorption edge: Effect of upconversion agent on the photocatalytic activity of Bi2WO6. Appl Catal B Environ 2010; 101: 68-73.

[19] Tian Y, Zhang L, Zhang J. A superior visible light-driven photocatalyst: Europium-doped bismuth tungstate hierarchical microspheres. J Alloys Compd 2012; 537: 24-28.

[20] Xu L, Gu D, Chang X, Chai L, Li Z, Jin X, Sun S. Rare-earth-doped tungsten oxide microspheres with highly enhanced photocatalytic activites. Ceram Int 2017; 43: 10263-10269.

[21] Li H, Hao H, Jin S, Guo W, Hu X, Hou H, Zhang G, Yan S, Gao W, Liu G. Hydrothermal synthesis and infrared to visible up-conversion luminescence of $\mathrm{Ho}^{3+} / \mathrm{Yb}^{3+}$ co-doped $\mathrm{Bi}_{2} \mathrm{WO}_{6}$ nanoparticles. Adv Powder Technol 2018; 29: 1216-1221.

[22] Xu X, Ge Y, Li B, Fan F, Wang F. Shape evolution of Eu-doped $\mathrm{Bi}_{2} \mathrm{WO}_{6}$ and their photocatalytic properties. Mater Res Bull 2014; 59: 329-336.

[23] Jha K, Jayasimhadri M. Structural and emission properties of $\mathrm{Eu}^{3+}$-doped alkaline earth zincphosphate glasses for white LED applications. J Am Ceram Soc 2017; 100: 1402-1411.

[24] Guan M, Sun J, Tao F, Xu Z. A host crystal for the rare-earth ion dopants: Synthesis of pure and ln-doped urchinlike $\mathrm{BiPO}_{4}$ structure and its photoluminescence. Cryst Growth Des 2008; 8: 2694 2697.

[25] Li Y-Y, Cheng W-D, Zhang H, Lin C-S, Zhang W-L, Geng L, Chai G-L, Luo Z-Z, He Z-Z. A series of novel rare-earth bismuth tungstate compounds $\mathrm{LnBiW}_{2} \mathrm{O}_{9}(\mathrm{Ln}=\mathrm{Ce}, \mathrm{Sm}, \mathrm{Eu}, \mathrm{Er})$ : synthesis, crystal structure, optical and electronic properties. Dalt Trans 2011; 40: 7357-7364.

[26] Feteira A, Sinclair DC. Microwave Dielectric Properties of Low Firing Temperature $\mathrm{Bi}_{2} \mathrm{~W}_{2} \mathrm{O}_{9}$ Ceramics. J Am Ceram Soc 2008; 91: 1338-1341.

[27] Tortosa M, Mollar M, Mari B. Synthesis of ZnCdO thin films by electrodeposition. J Cryst Growth 2007; 304: 97-102.

[28] Xu A-W, Gao Y, Liu H-Q. The Preparation, Characterization, and their Photocatalytic Activities of Rare-Earth-Doped $\mathrm{TiO}_{2}$ Nanoparticles. J Catal 2002; 207: 151-157.

[29] Amano F, Nogami K, Ohtani B. Enhanced photocatalytic activity of bismuth-tungsten mixed oxides for oxidative decomposition of acetaldehyde under visible light irradiation. Catal Commun 2012; 20: 12-16.

[30] Brown E, Hanley CB, Hömmerich U, Bluiett A. G, Trivedi SB. Spectroscopic study of neodymium doped potassium lead bromide for mid-infrared solid state lasers. J Lumin 2013; 133: 244-248.

[31] Yıldırım C, Birer Ö. Ultraviolet upconversion spectra of sonochemically synthesized doped $\mathrm{NaYF}_{4}$ crystals. Chem Phys 2014; 445: 46-52.

[32] Reszczyńska J, Grzyb T, Sobczak JW, Lisowski W, Gazda M, Ohtani B, Zaleska A. Visible light activity of rare earth metal doped $\left(\mathrm{Er}^{3+}, \mathrm{Yb}^{3+}\right.$ or $\left.\mathrm{Er}^{3+} / \mathrm{Yb}^{3+}\right)$ titania photocatalysts. Appl Catal B Environ 2015; 163: 40-49.

[33] Goodall JBM, Illsley D, Lines R, Makwana NM, Darr JA. Structure-property-composition 
relationships in doped zinc oxides: Enhanced photocatalytic activity with rare earth dopants. ACS Comb Sci 2015; 17: 100-112.

[34] Podhorodecki A, Nyk M, Misiewicz J, Strek W. Optical investigation of the emission lines for Eu ${ }^{3+}$ and $\mathrm{Tb}^{3+}$ ions in the GaN powder host. J Lumin 2007; 126: 219-224.

[35] Jayaramaiah JR, Lakshminarasappa BN, Nagabhushana BM. Luminescence studies of europium doped yttrium oxide nano phosphor. Sensors Actuators, B Chem 2012; 173: 234-238.

[36] Gupta SK, Ghosh PS, Pathak N, Kadam RM. Why host to dopant energy transfer is absent in the $\mathrm{MgAl}_{2} \mathrm{O}_{4}: \mathrm{Eu}^{3+}$ spinel? And exploring $\mathrm{Eu}^{3+}$ site distribution and local symmetry through its photoluminescence: interplay of experiment and theory. RSC Adv 2016; 6: 42923-42932.

[37] Gupta SK, Ghosh PS, Sahu M, Bhattacharyya K, Tewari R, Natarajan V. Intense red emitting monoclinic $\mathrm{LaPO}_{4}: \mathrm{Eu}^{3+}$ nanoparticles: host-dopant energy transfer dynamics and photoluminescence properties. RSC Adv 2015; 5: 58832-58842.

[38] Kumar BV, Veldurthi NK, Reddy JR, Vithal M. Solvothermal synthesis, characterisation, luminescence and photocatalytic activity of $\mathrm{Bi}_{2} \mathrm{WO}_{6}: \mathrm{Eu}$ nanocrystals. Micro Nano Lett 2012; 7 : 544.

[39] Mączka M, Macalika L, Hanuza J. Raman and IR spectra of the cation-deficient Aurivillius layered crystal $\mathrm{Bi}_{2} \mathrm{~W}_{2} \mathrm{O}_{9}$. J Raman Spectrosc 2009; 40: 2099-2103.

[40] Boronat C, Rivera T, Garcia-Guinea J, Correcher V. Cathodoluminescence emission of REE (Dy, Pr and Eu) doped $\mathrm{LaAlO}_{3}$ phosphors. Radiat Phys Chem 2017; 130: 236-242.

[41] Shaban YA, Khan SUM. Photoresponse of visible light active CM-n-TiO 2, HM-n-TiO 2 , CM-n$\mathrm{Fe}_{2} \mathrm{O}_{3}$, and CM-p- $\mathrm{WO}_{3}$ towards water splitting reaction. Int J Photoenergy 2012; 2012. 